\title{
AUTOMATED EVALUATION OF URETHRAL OBSTRUCTION
}

\author{
R. VAN MASTRIGT, PH.D. \\ M. KRANSE
}

From the Department of Urology-Urodynamics, Erasmus University Rotterdam, Rotterdam, The Netherlands

\begin{abstract}
The measurement of detrusor pressure and flow rate during voiding is the only way to objectively measure or grade infravesical obstruction. The resulting data cannot be interpreted easily. Manual as well as automatic methods have been introduced to derive one or several factors or parameters to quantify urethral resistance. A number of these methods are described in this overview. Since automatic methods involving computers guarantee uniform, unbiased, and objective processing of data, besides enabling the use of (statistical) methods that take into account more than one or two of the measured pressure and flow rate values, emphasis is on these methods, Some clinical results obtained with such automatic methods are discussed to illustrate the clinical value and possible impact on diagnosis and evaluation of treatment of lower urinary tract disorders.
\end{abstract}

The object of urodynamics is to derive diagnostically relevant information on the function of the urinary tract using physical means. These involve the measuring of physical variables such as pressures, volumes, and flow rates. The measured variables carry diagnostically relevant information which should somehow be abstracted.

In some cases the information can be read directly from a chart recording. For instance, bladder capacity can be read directly from a time chart showing infused volume and measured pressures during filling cystometry. In other cases the measured variables or signals are a convoluted representation of the diagnostic information. The latter applies to diagnosing urethral obstruction. Whether or not a patient is obstructed cannot be read directly from the paper charts produced during urodynamic investigation.

Consensus exists that infravesical obstruction can only be diagnosed urodynamically from simultaneous measurements of detrusor pressure and flow rate during voiding, a pressure-flow study. In extreme cases the diagnosis is straightforward. If the maximum flow rate is very high and detrusor pressure is very low, the patient obviously is unobstructed. If the flow rate is very low and detrusor pressure very high the patient is obstructed. ${ }^{1}$

Submitted: June 2, 1993, accepted: June 4, 1993
In the majority of cases (patients with moderate flow rates and/or moderate pressures, or low flow rates and/or low pressures, or high flow rates and high pressures), such a simple direct diagnosis is not possible. Therefore, using a nomogram has been proposed. ${ }^{2}$ By plotting the maximum flow rate and the associated detrusor pressure value in an $x-y$ diagram, each patient can be represented by a single dot. Borderlines can be defined to try to best separate the dots from obstructed and unobstructed patients, a gray zone can be added. Logically such nomograms imply the assumption that patients are obstructed or not, which is an oversimplification. Rather, each patient (or healthy subject) is obstructed to some degree, or has a certain urethral resistance. Especially when trying to evaluate the effect of less than drastic treatment, but also for the design of flexible treatment planning, it is necessary to use a method for grading or measuring obstruction more accurately than in terms of obstructed or not. To this end, urethral resistance factors or parameters have been developed. Such parameters are calculated from pressure-flow studies and are the subject of this review.

Following a short summary of the theoretical basis a number of these parameters as published in recent years will be discussed from a conceptual point of view. As deriving the parameters from the measured data requires calculation, most 


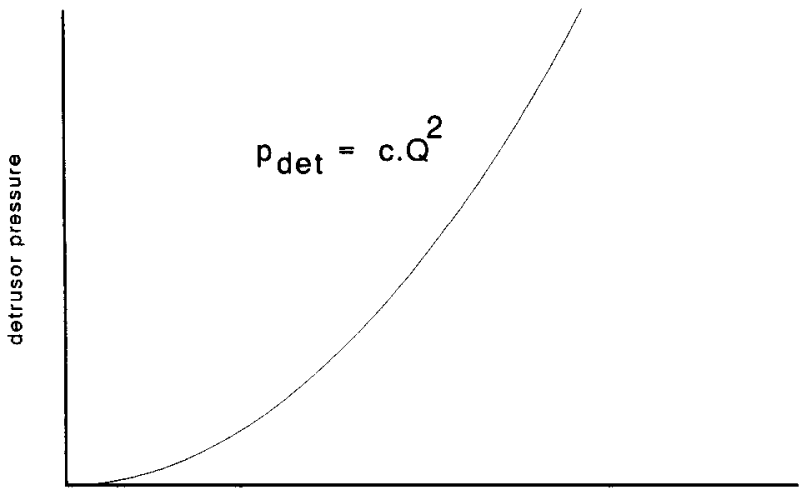

flow-rate

FIGURE 1. If the bladder outlet were a hole in the bladder, the pressure-flow plot would take a simple quadratic form.

of the methods involve the use of a computer. Apart from being efficient, computer usage ensures objectivity, thus enabling statistical processing for instance to test the effect of pharmacologic treatment. Finally, examples of clinical application of urethral resistance/obstruction parameters and a limited clinical comparison of a number of different parameters will be discussed.

\section{THEORY}

Most simply the bladder outlet during voiding can be modeled as a hole in the urinary bladder. ${ }^{3}$ In such an oversimplified case the relation between the detrusor pressure and the flow rate through the hole during voiding would be quadratic. Figure 1 shows an example of such a quadratic relation. The classic urethral resistance factor $\mathrm{p} / \mathrm{Q}^{2}$ was derived from this theoretical relation. ${ }^{4}$ Figure 2 shows a typical example of real pressure-flow data measured in a patient; Figure 3 is the pressure-flow plot derived from these data.

There are two obvious differences between Figure 3 and Figure 1. First, Figure 3 does not show one unique relationship between detrusor pressure and flow rate. In fact, at each flow-rate value between 0 and the maximum of approximately 14 $\mathrm{mU} / \mathrm{s}$ several detrusor pressure values were measured at different moments in time. This results from the fact that the urethra is not a passive structure, but changes its properties throughout voiding. Normally, and in this case, at the end of voiding it is more relaxed than at the onset. This implies that at each flow-rate value in Figure 3 the lowest pressures measured represent the most relaxed state of the urethra. It is this most relaxed state which represents the anatomic properties of the urethra to the highest degree. Therefore, in
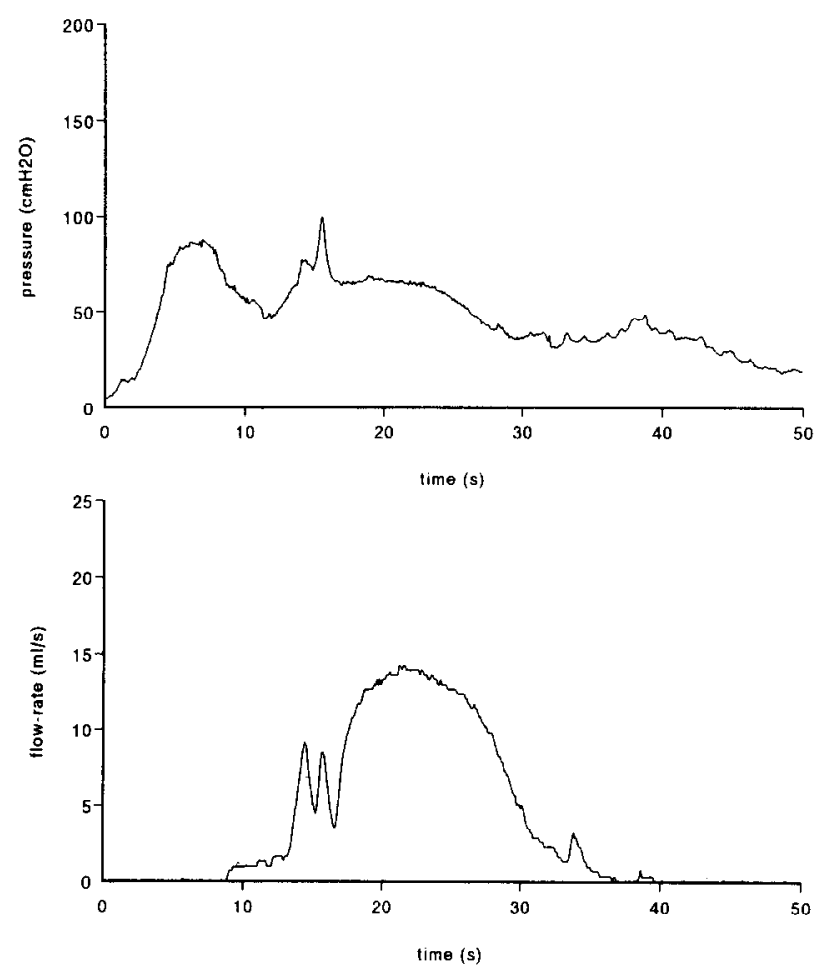

FIGURE 2. Detrusor pressure and flow rate as a function of time, measured during voiding cystometry.

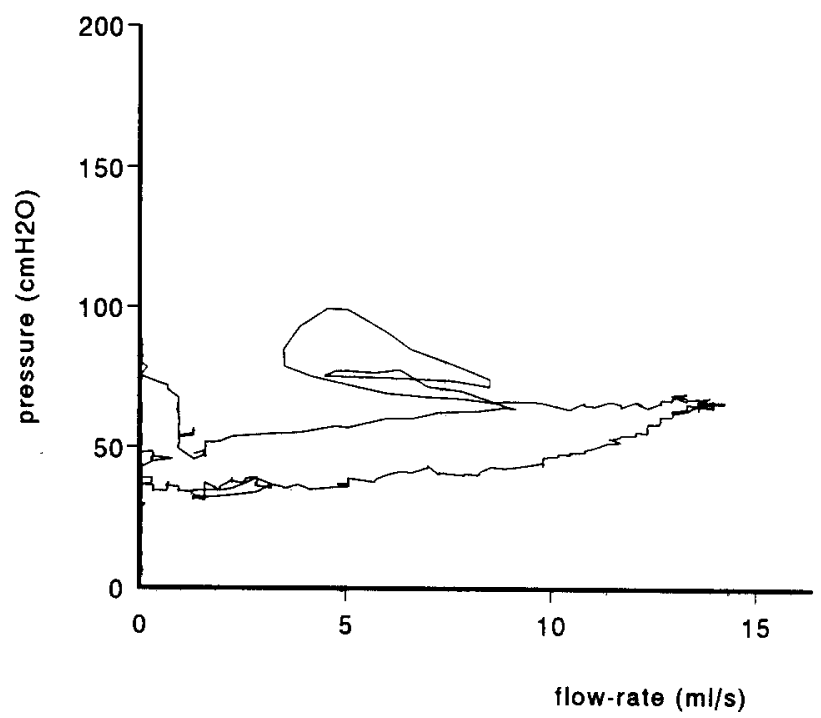

FIGURE 3. Detrusor pressure plotted as a function of measured flow rate, same data as in Figure 2.

Figure 3 the lowest part, the part of the curve closest to the flow-rate axis represents the (anatomic) urethral resistance of this patient.

Comparing only this "underside" of Figure 3 to Figure 1 we notice the second obvious difference. The real data do not pass through the origin. This is caused by the fact that the urethra is not a hole in the bladder wall, but a complicated structure that must be described as a flexible collapsible tube. A certain minimum pressure is needed to open this collapsed tube and keep it open during 


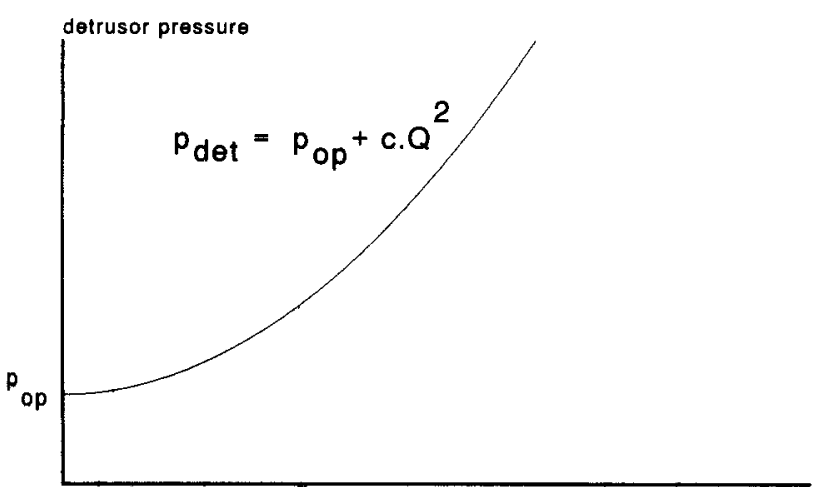

flow-rate

FIGURE 4. A modified quadratic relation between pressure and flow rate that takes into account the threshold pressure necessary to keep the urethra open.

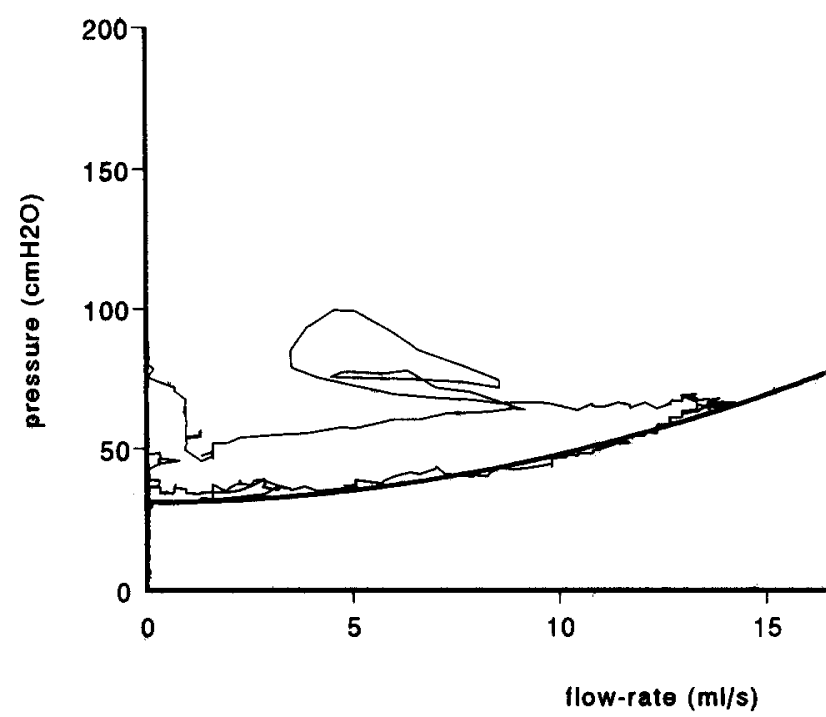

FIGURE 5. The equation illustrated in Figure 4 fitted to the data shown in Figure 3.

voiding. This minimum pressure is called the urethral opening pressure and, in Figure 3, it is in the order of $30 \mathrm{~cm}$ water.

Rather confusingly, the opening pressure is very often not the pressure at which the urethra opened when voiding started, which is called the detrusor opening pressure. ${ }^{1}$ Figure 2 shows that in this case voiding started at a detrusor opening pressure in the order of $70-80 \mathrm{~cm}$ water, which is more than twice the urethral opening pressure of $30 \mathrm{~cm}$ water. Again this results from the fact that at the onset of micturition the urethra was not fully relaxed. Taking into account a nonzero urethral opening pressure a theoretical pressure-flow relationship as in Figure 4 is derived. This has been called PURR. ${ }^{5}$ Figure 5 shows that this theoretical relationship describes the measured data of Figure 2 adequately.

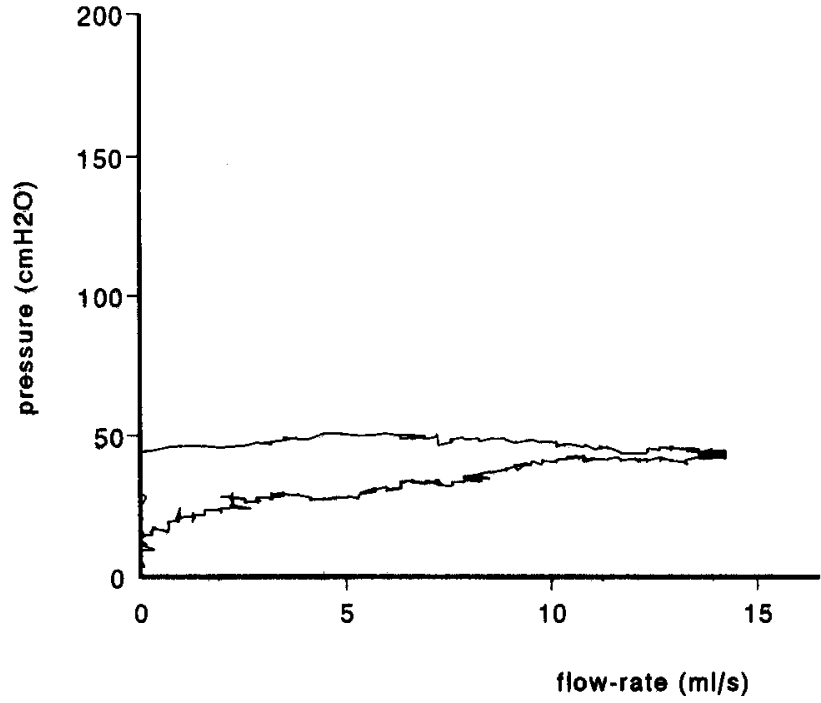

FIGURE 6. A pressure-flow curve that cannot be fitted with the quadratic relation as in Figure 4.

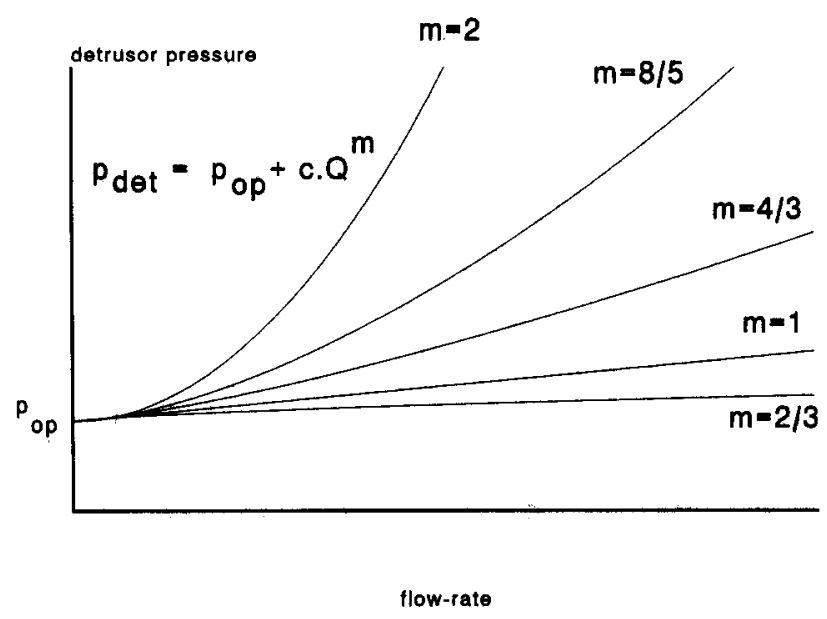

FIGURE 7. Relations between pressure and flow rate that result from a collapsible tube model for the urethra. In this model the cross-sectional area of the urethral lumen depends on the pressure. Pressure-area relation for a given urethra determines which of the shown relations is valid; $m=2$ represents a completely unelastic urethra as in Figure 4.

Although it accounts for opening of the urethra, the fitted relation is still based on rigid pipe hydrodynamics: as long as the urethra is open it has a constant cross-sectional area. In reality this is usually not the case. The urethra is an elastic structure, and its cross-sectional area depends to some degree on the pressure. As a consequence pressure-flow plots often take a form that cannot adequately be described by the quadratic relation shown in Figure 4. Figure 6 shows an example. Taking a pressure-dependent change in cross-sectional area of the urethra into account it is possible to model the urethra as an elastic collapsible tube. ${ }^{6}$ Such a model results in a pressure-flow relationship that is not quadratic but has a variable form depending on the elasticity of the urethra. Figure 7 shows a number of different theoretical pressure-flow relationships that can be derived in 


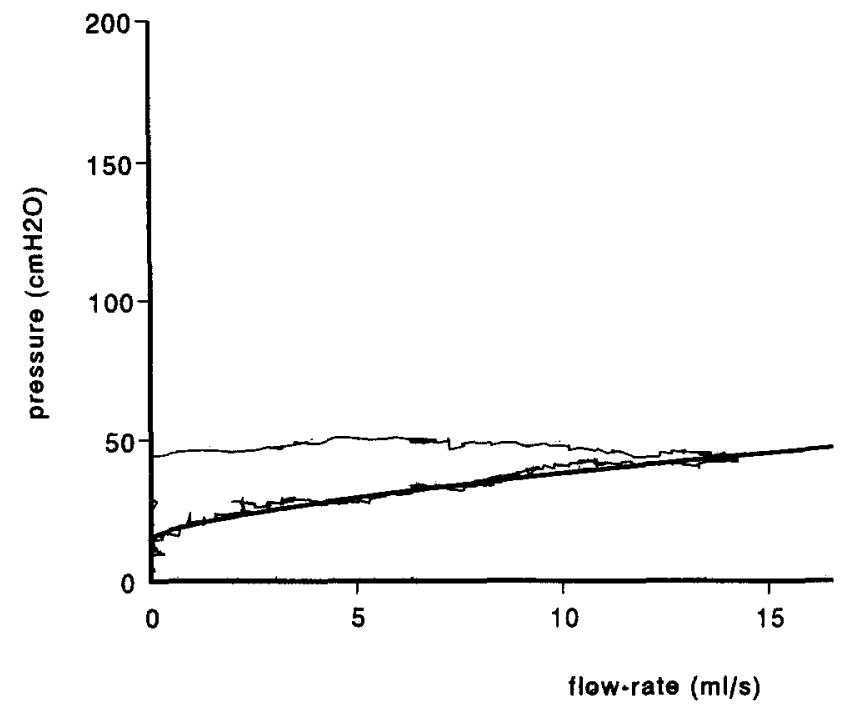

FIGURE 8. The pressure flow-plot data of Figure 6 fitted with the model denoted $m=2 / 3$ in Figure 7 .

this way. ${ }^{7,8}$ The one with $\mathrm{m}=2 / 3$ fits the data of Figure 6 adequately (Fig. 8).

In the following section we will see that for determining one practical combined urethral resistance parameter this model has drawbacks as a result of its statistical properties. Therefore, an alternative mathematical method of describing pressure-flow relationships in terms of orthogonal polynomials has been introduced. An orthogonal polynomial is, in fact, an addition of a number of the formulas illustrated in Figure 7 in such a way that the terms are statistically independent. ${ }^{9}$

\section{PRACTICAL PARAMETERS}

Fitting the mathematical relations or models described in the previous section to pressure-flow data measured in patients results in a number of parameters that define the fitted curve. The quadratic curve (Fig. 1) is defined by one parameter, its steepness; the PURR (Fig. 4) is defined by an opening pressure and a steepness (in the cited references only the opening pressure is used as a parameter); and the collapsible tube model (Fig. 7) is defined by an opening pressure, a steepness, and a form factor or exponent $m$. The orthogonal polynomial model is defined by a number of parameters depending on the number of terms included in the model; in the cited case three terms were used, defined by three parameters.

In many cases it is desirable to have one single parameter that can be used as a measure of obstruction or urethral resistance. Such a single parameter enables straightforward comparison of patient data and (statistical) evaluation of the ef- fect of treatment, which is difficult when several parameters are used. For instance if we use the two-parameter PURR model of Figure 4, and as a result of treatment the opening pressure of a patient decreases but his steepness increases, then it is unclear if the patient's degree of obstruction has decreased or increased. Only the simple quadratic model (Fig. 1) yields a single parameter; however, we have seen that this model does not adequately describe clinical data and therefore the resulting resistance factor $\mathrm{p} / \mathrm{Q}^{2}$ is unreliable. Two different methods have been used to reduce or combine the sets of parameters which result from using the other three models to one urethral resistance parameter.

In the first approach the PURR model of Figure 4 was fitted to pressure-flow data of a mixed group of patients. ${ }^{10}$ An experimental statistical relation was established between the two parameters of the model, opening pressure and steepness. By inserting this relation into the model an equation with only one parameter was derived. This one parameter has been called URA, and it can be calculated from any point along the pressure-flow curve. In all clinical applications the point of maximum flow rate and associated detrusor pressure is used.

In a second approach the parameters from the model shown in Figure 7 and the parameters from the orthogonal polynomial model were reduced to one urethral resistance parameter by using a statistical method called Fishers linear discriminant. In this method pressure-flow measurements are represented by a dot in an $n$-dimensional space ( $\mathrm{n}$ is the number of parameters of the model) and the dots are projected on a line through the origin. The line is rotated until it best separates a group of obstructed and unobstructed patients. The distance along the line then is the new combined single obstruction parameter. This method was applied to a continuous version of the model of Figure 7 . In the original publications ${ }^{7,8}$ the authors used a discrete number of different values for the parameter $m$ describing the form of the model (Fig. 7). When applying Fishers linear discriminant method a continuous version of the model was used, where the form parameter $m$ could have any value. This resulted in very unreliable parameters, as these were not statistically independent in one measurement. This means that one and the same pressure-flow plot could be fitted with several curves with completely different parameters. ${ }^{11}$ The orthogonal polynomial model did not suffer from this problem as the parameters of this model are designed to be statistically 


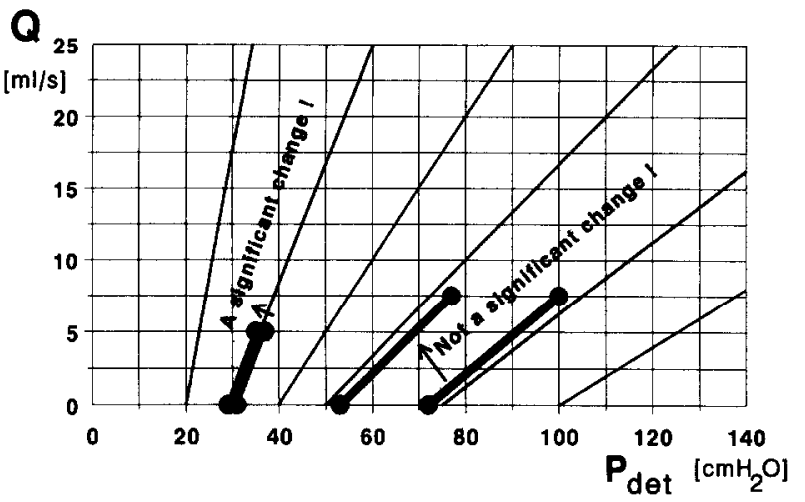

FIGURE 9. Pressure-flow nomogram paraphrased from Schäfer et al. ${ }^{14}$ To illustrate the variable resolution of this method 2 hypothetical patients are plotted in nomogram. In the patient on the right detrusor pressure at maximum flow rate decreased from $100 \mathrm{~cm}$ water to $75 \mathrm{~cm}$ water at an unchanged maximum flow rate of $7.5 \mathrm{~mL} / \mathrm{s}$ in response to a hypothetical treatment. This is not a significant change according to the nomogram. In the patient on left detrusor pressure at maximum flow rate decreases from $38 \mathrm{~cm}$ water to 36 $\mathrm{cm}$ water at an unchanged maximum flow rate of 5 $\mathrm{mL}$ s in response to a hypothetical treatment. This is a significant change according to the nomogram.

independent. Reduction of the parameters of the polynomial model using Fishers linear discriminant method resulted in the single parameter OBI. ${ }^{12}$

In the following section some examples of clinical application of the parameters URA and OBI will be given. For a complete understanding of these results it is sometimes necessary to take differences in the contractility of patients' bladders into account. In these examples contractility was measured using the parameter $\mathrm{w}_{\max },{ }^{13}$ which is an approximation of the power generated by the bladder per bladder wall surface area.

In addition to the described computer-based methods for measuring the degree of infravesical obstruction, a manual method has been described..$^{14}$ The method involves reading the maximum flow rate and associated detrusor pressure, and the lowest pressure at which voiding occurs from the paper chart of a pressure-flow study, plotting these points in a nomogram, and connecting them with a straight line which should then fall in one out of seven categories. Figure 9 shows an example of this nomogram. As the method involves manual interpretation of pressure-flow data it is subjective and should strictly speaking not be included in this overview. Its limited number of classes or categories, however, enables the discussion of advantages and disadvantages of such a discrete method compared with

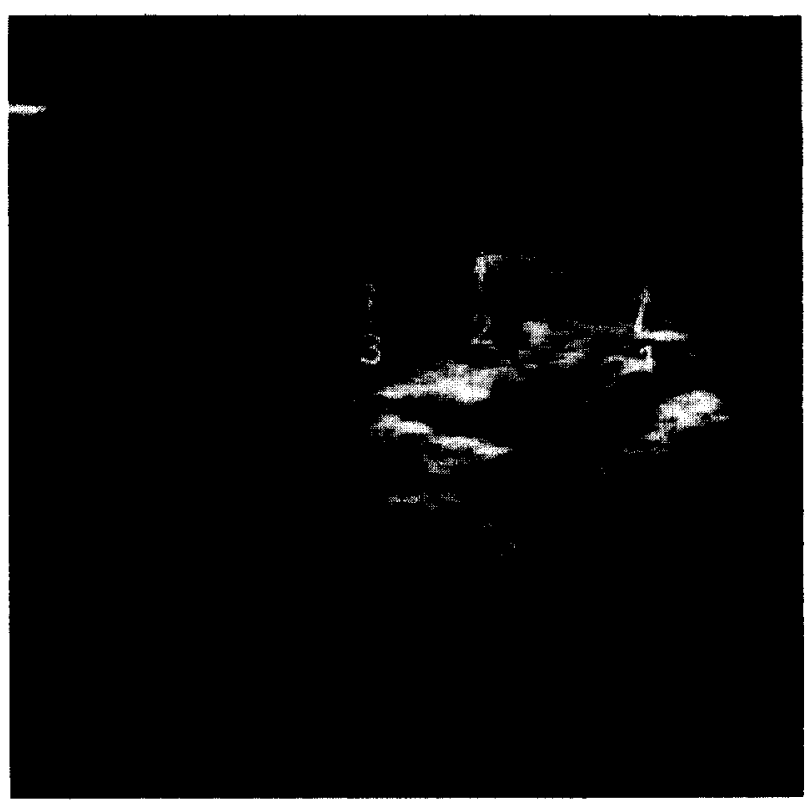

FIGURE 10. Transrectal ultrasound image of prostatic urethra during voiding. The diameter of the urethra was measured at three locations indicated with arrows. These diameters correlated significantly with urethral resistance parameters.

the other methods described which measure urethral resistance on a continuous scale. For this reason this method will be briefly discussed in the last section of this overview.

\section{SOME CLINICAL RESULTS}

In a number of clinical studies the urethral resistance parameters URA and OBI, and the contractility parameter $\mathrm{w}_{\max }$ have been calculated. With some exceptions, when parameters were calculated retrospectively, this was done immediately following each urodynamic measurement, using a special computer program. This program (CLIM $^{15-18}$ ) enables connection of a personal computer to urodynamic equipment and storage, retrieval, and analysis of urodynamic data.

Figure 10 shows a transrectal ultrasound recording of bladder, bladder neck, and prostatic urethra at the moment of maximum flow rate. In a small pilot study of 10 patients ${ }^{19}$ the diameter of the prostatic urethra was measured from recordings like these at the apex, the midurethra, and the bladder neck, as shown by the arrows in the figure. Spearman's rank correlations between these three diameters and URA were $-0.70(\mathrm{p}=0.013)$, $-0.48(\mathrm{p}=0.079)$, and $-0.71(\mathrm{p}=0.011)$. Rank correlations with OBI were: $-0.62(p=0.027)$ $-0.60(\mathrm{p}=0.032)$, and $-0.60(\mathrm{p}=0.032)$. None of the diameters correlated significantly with the 
TABLE I. Residual urine (RES), maximum flow rate $\left(Q_{\max }\right)$, detrusor pressure at maximum flow rate $P\left(Q_{\max }\right)$, contractility $\left(w_{\max }\right)$, and urethral resistance (URA) in 19 obstructed patients before and after TURP*

\begin{tabular}{|c|c|c|c|c|c|c|}
\hline \multirow[b]{2}{*}{ Parameters } & \multicolumn{3}{|c|}{ Preoperative Measurements } & \multicolumn{3}{|c|}{ Postoperative Measurements } \\
\hline & $\begin{array}{l}\text { Postop } \\
\text { RES }<50\end{array}$ & U-test & $\begin{array}{l}\text { Postop } \\
\text { RES }>50\end{array}$ & $\begin{array}{l}\text { Postop } \\
\text { RES }<50\end{array}$ & U-test & $\begin{array}{c}\text { Postop } \\
\text { RES }>50\end{array}$ \\
\hline$\overline{R E S}$ & & & & & & \\
\hline$(\mathrm{mL})$ & $182 \pm 130$ & 0.12 & $270 \pm 128$ & $12 \pm 18$ & & $141 \pm 89$ \\
\hline $\mathrm{O}_{\max }(\mathrm{mL} / \mathrm{s})$ & $5.5 \pm 2.1$ & 0.27 & $6.8 \pm 3.2$ & $17.3 \pm 7.3$ & 0.27 & $15.5 \pm 10.6$ \\
\hline $\begin{array}{l}P\left(Q_{\max }\right) \\
\quad(\mathrm{cm} \text { water })\end{array}$ & $92 \pm 30$ & 0.014 & $62 \pm 13$ & $36 \pm 10$ & 0.13 & $41 \pm 9$ \\
\hline $\begin{array}{l}W_{\max } \\
\left(W / m_{2}\right) \\
\text { URA }\end{array}$ & $13.0 \pm 4.4$ & 0.020 & $9.0 \pm 1.5$ & $12.3 \pm 4.5$ & 0.042 & $8.9 \pm 3.9$ \\
\hline $\begin{array}{l}\text { (cm water) } \\
\text { Pts. }\end{array}$ & $\begin{array}{l}58 \pm 21 \\
N=12\end{array}$ & 0.069 & $\begin{array}{c}40 \pm 14 \\
N=7\end{array}$ & $\begin{array}{l}15 \pm 5 \\
N=12\end{array}$ & 0.33 & $\begin{array}{c}18 \pm 5 \\
N=7\end{array}$ \\
\hline
\end{tabular}

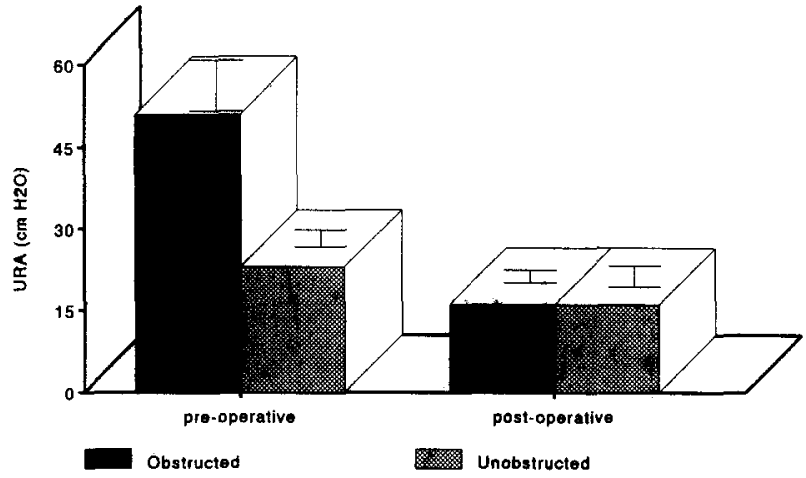

FIGURE 11. Average values and standard deviations for the urethral resistance parameter URA in a group of 29 patients before and after transurethral resection of the prostate.

contractility parameter $\mathrm{w}_{\max }$. These data confirm that the urethral resistance as quantified by the parameters URA and OBI is determined to a large degree by the urethral diameter during voiding, and that the contractility parameter $\mathrm{w}_{\max }$ is not significantly biased by changes in urethral diameter.

Figure 11 shows URA values in a series of 29 patients before and after transurethral resection of the prostate (TURP). ${ }^{20,21}$ These patients were selected using conventional clinical criteria. It was found that this population consisted of two groups: a group of obstructed patients with high URA before the operation and a significantly decreased URA value afterward $(N=19)$, and a smaller but significant group ( $\mathrm{N}=10$, approximately $35 \%$ ) of unobstructed patients with low URA values both before and after the operation.
That about 25 percent of patients with symptoms of prostatism is urodynamically not obstructed has been confirmed in other studies. ${ }^{22}$ The outcome of surgery in terms of subjective symptomatology is less favorable in these patients, which provides strong arguments for including preoperative testing in terms of the described parameters before prostatic surgery. ${ }^{21}$ Average values for the contractility parameter $\mathrm{w}_{\max }$ in this patient group are shown in Table ${ }^{23}$

Two groups were made from the 19 obstructed patients: one group that postoperatively still had a significant amount of residual urine (average $>50$ $\mathrm{mL}$ ), and one group that postoperatively had no significant residual. Table I shows that postoperatively there was no difference in the degree of obstruction of these groups of patients, so that the difference in postoperative voiding efficiency could only have been caused by the bladder. Indeed postoperatively significantly lower values for the contractility parameter $\mathrm{w}_{\max }$ were found in the group with significant residuals. Interestingly, this difference also existed in preoperative $\mathrm{w}_{\max }$ values so that the postoperative residual urine could have been predicted preoperatively using this parameter.

Table II shows apart from the change in URA in response to TURP in obstructed patients also the responses of 14,16 , and 15 patients that were treated with placebo and 2 and $4 \mathrm{mg}$ of Doxazosine,$^{24}$ an alpha blocker. Table II shows that although the effect of this drug is dramatically smaller than that of the operation, there is nevertheless a significant reduction in the parameter 
TABLE II. Effect of treatment for BPH on value of urethral resistance parameter URA*

\begin{tabular}{lllll}
\hline $\begin{array}{c}\text { Before } \\
\text { Treatment }\end{array}$ & \multicolumn{1}{c}{ Treatment } & $\begin{array}{c}\text { After } \\
\text { Treatment }\end{array}$ & $\begin{array}{c}\text { No. of } \\
\text { Pts. }\end{array}$ & $\begin{array}{c}\text { Wilcoxon } \\
\text { Test }\end{array}$ \\
\hline $40 \pm 21$ & Placebo & $39 \pm 23$ & 14 & $\mathrm{p}=0.51$ \\
$51 \pm 20$ & TURP & $16 \pm 5$ & 19 & $\mathrm{p}<0.0001$ \\
$53 \pm 21$ & $2 \mathrm{mg}$ Doxazosin & $39 \pm 18$ & 16 & $\mathrm{p}=0.03$ \\
$48 \pm 21$ & $4 \mathrm{mg}$ Doxazosin & $41 \pm 18$ & 15 & $\mathrm{p}=0.03$ \\
*Average values \pm standard deviations in cm water: Significance of Wilcoxon signed \\
rank test is also indicated.
\end{tabular}

TABLE III. Effect of treatment for $B P H$ on value of urethral resistance parameter $O B I^{*}$

\begin{tabular}{llccl}
\hline $\begin{array}{c}\text { Before } \\
\text { Treatment }\end{array}$ & \multicolumn{1}{c}{ Treatment } & $\begin{array}{c}\text { After } \\
\text { Treatment }\end{array}$ & $\begin{array}{c}\text { No. of } \\
\text { Pts. }\end{array}$ & $\begin{array}{c}\text { Wilcoxon } \\
\text { Test }\end{array}$ \\
\hline $68 \pm 23$ & Placebo & $62 \pm 27$ & 14 & $p=0.30$ \\
$83 \pm 34$ & TURP & $34 \pm 10$ & 19 & $p=0.0001$ \\
$88 \pm 31$ & 2 mg Doxazosin & $71 \pm 28$ & 16 & $p=0.16$ \\
$94 \pm 35$ & 4 mg Doxazosin & $80 \pm 30$ & 15 & $p=0.04$
\end{tabular}

*Average values \pm standard deviations in $\mathrm{cm}$ water. Significance of Wilcoxon signed rank test is also indicated.

URA both in the patient group treated with $2 \mathrm{mg}$ and in the group treated with $4 \mathrm{mg}$.

Table III shows average values and standard deviations for the urethral resistance parameter $\mathrm{OBI}$ in the same groups. Apart from the group treated with TURP, this parameter only shows a significant change in the 4-mg group.

Table IV not only shows values for the contractility parameter $\mathrm{w}_{\max }$ for the same groups of patients, but also for two groups of 6 children treated with oxyphenonium bromide and oxybutynin hydrochloride. ${ }^{25}$ These children were treated for reflux related to bladder hyperactivity.
The treatment with oxybutynin was successful in that a significant reduction in the reflux grade was found; the treatment with oxyphenonium was not. Table IV shows that this finding was correlated with a significant reduction in the bladder contractility as quantified by $\mathrm{w}_{\max }$ when applying oxybutynin. All other treatments had no significant effect on this contractility parameter, illustrating that it is not biased by even dramatic changes in urethral resistance.

\section{COMPARISON OF METHODS FOR QUANTIFYING OBSTRUCTION}

The ability to classify obstructed and nonobstructed patients, the resolution (the minimum change in bladder outlet resistance that can be detected) and the bias by contractility of the parameters URA, OBI, and the LPURR nomogram ${ }^{14}$ have been compared in a group of 180 measurements in 29 TURP patients. ${ }^{26}$

The LPURR nomogram, which is not an automatic method and should therefore strictly speaking not be discussed here, has briefly been described in the section on Practical Parameters. Figure 9 shows a paraphrased version of this nomogram. In the comparison, those patients in whom no unanimous (according to all parameters) decrease in parameter values occurred after TURP were classified as preoperatively unobstructed. The total number of correctly classified measurements based on this classification is shown in Figure 12, which also shows the performance of classification based on the maximum flow-rate $\mathrm{Q}_{\max }$ alone, and a classification based on throwing dice. It follows that using $Q_{\max }$ alone approximately 75 percent of measurements were correctly classified, and using LPURR, URA, and OBI approximately 90 percent were correctly classified.

TABLE IV. Effect of treatment of different patient groups on bladder contractility parameter $\mathrm{w}_{\max }{ }^{*}$

\begin{tabular}{lllcc}
\hline $\begin{array}{c}\text { Before } \\
\text { Treatment }\end{array}$ & \multicolumn{1}{c}{$\begin{array}{c}\text { Type of } \\
\text { Treatment }\end{array}$} & $\begin{array}{c}\text { After } \\
\text { Treatment }\end{array}$ & $\begin{array}{c}\text { No. of } \\
\text { Pts. }\end{array}$ & $\begin{array}{c}\text { Wilcoxon } \\
\text { Test }\end{array}$ \\
\hline $12.7 \pm 4.3$ & Placebo & $11.0 \pm 3.3$ & 14 & $\mathrm{NS}$ \\
$11.6 \pm 4.1$ & TURP & $11.0 \pm 4.5$ & 19 & $\mathrm{NS}$ \\
$12.9 \pm 5.9$ & 2 mg Doxazosin & $12.4 \pm 4.7$ & 17 & $\mathrm{NS}$ \\
$15.3 \pm 6.2$ & 4 mg Doxazosin & $13.8 \pm 4.9$ & 16 & $\mathrm{NS}$ \\
$16.2 \pm 7.5$ & Oxyphenonium bromide & $17.4 \pm 4.1$ & 6 & $\mathrm{NS}$ \\
$18.2 \pm 4.6$ & Oxybutynin hydrochloride & $12.1 \pm 5.2$ & 6 & $\mathrm{p}=0.028$
\end{tabular}

${ }^{*}$ Average values \pm standard deviations are shown. Also significance of Wilcoxon signed rank test is indicated (NS $=$ not significant). 


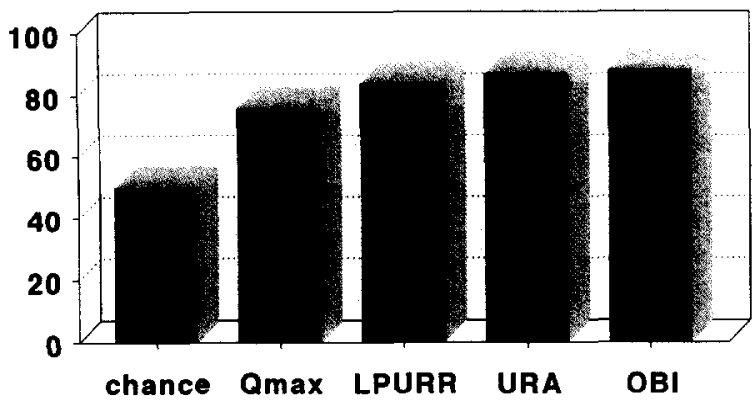

FIGURE 12. Percentage of correctly classified patients using five different methods of classifying patients as obstructed or nonobstructed in a group of 29 TURP patients: (1) chance (throwing dice); (2) using maximum flow rate only; (3) using the LPURR nomogram (see Fig. 9); (4) and (5) using the urethral resistance parameters URA and $O B I$. The last three methods are based on pressure-flow measurements.

It should be noted that on applying the LPURR method it was found that in more than half of the measurements the line to be drawn crossed the category borders, making correct classification impossible. In these cases the method was "enhanced" by averaging categories, i.e., effectively increasing the number of categories. The small differences shown in this way between the LPURR, URA, and OBI methods can be interpreted in two ways. Either there are no large differences between the methods, or the differences do not show as a result of the test used. The latter is the case here. Two groups of extremely different patients have been constructed, and all methods perform equally in separating these.

A better criterion is to compare the ability of methods to discriminate small differences in bladder outlet resistance. URA and OBI have been shown to detect the difference in outlet resistance upon application of an alpha blocker (Doxazosin). ${ }^{24}$ The LPURR nomogram has been applied to a group of patients treated with indoramin and prazosin resulting in no significant differences. ${ }^{27}$ The authors conclude that "alpha-blockers . . . cannot reduce outflow obstruction in the majority (2/3) of patients." As such a reduction could be shown using the parameters URA and OBI however, it must be concluded that it is the LPURR nomogram method that failed, and not the drug.

This failure can easily be understood. Figure 9 shows schematically the hypothetical effect of treatment of 2 hypothetical patients. At the right side of the nomogram a patient has been drawn whose detrusor pressure at maximum flow rate decreases from 100 to $75 \mathrm{~cm}$ water at an un- changed maximum flow rate of $7.5 \mathrm{~mL}$. This is not a significant change according to the nomogram. At the left side of the nomogram a patient has been illustrated whose detrusor pressure at maximum flow rate decreases from 38 to $36 \mathrm{~cm}$ water at an unchanged maximum flow rate of 5 $\mathrm{mL} / \mathrm{s}$. This is a significant change according to the nomogram, as a border line is crossed. The arbitrary variation in resolution of the LPURR nomogram method as illustrated in Figure 9 severely limits its applicability.

A final aspect of the performance of URA, OBI, or LPURR that was tested is the degree to which these parameters are biased by contractility. It followed that LPURR is not (Spearman's rank correlation 0.00), URA is slightly $(r=-0.46)$, and OBI is hardly $(r=0.10)$ biased by contractility. 26,28

A common property of all these methods is that the patients' pressure-flow data are reduced to one number or category. This implies that it is possible to have two obviously different patients or measurements yielding the same parameter value. In the individual patient this has been called imprecise. ${ }^{2 y}$ It is, however, inherent to all methods that yield a single resistance parameter, even to those that have been especially developed to overcome this drawback. ${ }^{29}$ It is also essential in order to be able to rank patients and statistically test the effect of treatment. ${ }^{30}$

\section{CONCLUSIONS}

The measurement of detrusor pressure and flow rate during voiding is the only way to measure or grade infravesical obstruction objectively. The resulting data are difficult to interpret. A number of methods to derive one or a few urethral resistance factors or parameters from these data have been discussed. Apart from performance factors (how well can obstructed and unobstructed patients be discriminated, can small changes in resistance, e.g., in response to drug treatment be detected, are the parameters biased by bladder contractility) manual and automatic methods can be discriminated. Since automatic methods, involving computers, ensure objectivity and uniform data processing and provide the opportunity to take more than just one or two datapoints into account these must be preferred above manual methods involving nomograms.

A considerable body of evidence has been published that the computer-derived urethral resistance parameter URA is clinically very useful although it is slightly biased by bladder contractility. Newer approaches (e.g., the parameter $\mathrm{OBI}$ ) have been described that minimize this bias. 
R. van Mastrigt, PH.D.

P.O. Box 1738

3000 DR Rotterdam

The Netherlands

\section{REFERENCES}

1. Abrams P, Blaivas JG, Stanton SL, and Andersen JT: The standardization of terminology of lower urinary tract function. Scand J Urol Nephrol (Suppl) 114: 5-19, 1988.

2. Abrams PH, and Griffiths DJ: The assessment of prostatic obstruction from urodynamic measurements and from residual urine. Br J Urol 51: 129-134, 1979.

3. Schäfer W: Urcthral resistance? Urodynamic concepts of physiological and pathological bladder outlet function during voiding. Neurourol Urodyn 4: 161-201, 1985.

4. Pierce JM, Braun E, Sniderman AJ, and Lewis HY: The concept of resistance applied to the lower urinary tract. Surg Gynecol Obstet 116: 217-222, 1963.

5. Schäfer W: The contribution of the bladder outlet to the relation hetween pressure and flow rate during micturition, in Hinman F Jr (Ed): Benign Prostatic Hypertrophy. New York-Heidelberg-Berlin, Springer, 1983, pp 470-498.

6. Griffiths DJ: Urodynamics. The Mechanics and Hydrodynamics of the Lower Urinary Tract. Medical Physics Handbooks 4, Bristol, $\Lambda$ dam Hilger Ltd, 1980.

7. Spangberg A, Teriö H, Engberg A, and Ask P: Quantification of urethral function based on Griffiths model of flow through elastic tubes. Neurourol Urodyn 8: 29-52, 1989.

8. Teriö H, Spangberg A, Engberg A, and Ask P: Estimation of elastic properties in the urethral how controlling zone by signal analysis of urodynamic pressure/flow data. Med Biol Fng Comp 27: 314-321, 1989.

9. Kranse $M$, and van Mastrigt R: Fitting orthogonal polynomials to the lowest part of a pressure flow plot. Neurourol Urodyn 10: 290-291, 1991

10. Griffiths D, van Mastrigt R, and Bosch R: Quantification of urethral resistance and bladder function during voiding, with special reference to the effects of prostate size reduction on urethral obstruction due to BPH. Neurourol Urodyn 8: 17-27, 1989.

11. Kranse $M$, and van Mastrigt $R$ : An index for subvesical obstruction obtained from the lowest monotonically increasing part of a pressure flow plot. J Urol (in press).

12. Kranse $M$, van Mastrigt $R$ : The derivation of an obstruction index from a three parameter model fitted to the lowest part of the pressure flow plot. J Urol 145: 261A, 1991.

13. Griffiths DJ, Constantinou CE, and van Mastrigt R: Urinary bladder function and its control in normal females. Am J Physiol 251: R225-R230, 1986.

14. Schäfer W, Waterbär F, Langen PH, and Deutz FJ: A simplified graphic procedure for detailed analysis of detrusor and outlet function during voiding. Neurourol Urodyn 8 : 405-407, 1989.
15. van Mastrigt $R$ : A computer program for on-line measurement, storage, analysis and retrieval of urodynamic data. Comp Prog Biomed 18: 109-117, 1984.

16. van Mastrigt $\mathrm{R}$ : Urodynamic analysis using an on-line computer. Neurourol Urodyn 6: 206-207, 1987.

17. Rollema HJ, van Mastrigt R, and Janknegt RA: Urodynamic assessment and quantification of prostatic obstruction before and after transurethral resection of the prostate; standardization with the aid of the computer program CLIM. Urol Int (Suppl 1) 47: 52-54, 1991.

18. Rollema HJ, van Mastrigt R: Objective analysis of prostatism; a clinical application of the computer program CLIM. Neurourol Urodyn 10: 71-76, 1991. Erratum: Neurourol Urudyin 10: 267, 1991 .

19. Jansen $H$, van Mastrigt $R$ : Transrectal ultrasound of the prostatic urethra related to urodynamically assessed urethral resistance. Neurourol Urodyn 11: 401-403, 1992.

20. Rollema HJ, van Mastrigt R: Detrusor contractility before and after prostatectomy. Neurourol Urodyn 6: 220-221, 1987.

21. Rollema $\mathrm{HJ}$, van Mastrigt $\mathrm{R}$ : Improved indication and follow-up in transurethral resection of the prostate (TUR) using the computer program CLIM. J Urol 148: 111-116, 1992 .

22. Schäfer W, Noppeney R, Rübben $H$, and Lutzeyer W: The value of free flow rate and pressure/flow-studies in the routine investigation of $\mathrm{BPH}$ patients. Neurourol Urodyn 7 : 219-221, 1988

23. van Mastrigt $\mathrm{R}$, and Rollema $\mathrm{HJ}$ : Prognostic value of bladder contractility in prostatectomy. J Urol 148: 1856-1860, 1992.

24. Rollema HJ, Rosier P, Janknegt RA, and van Mastrigt R: Efficacy of alpha-blocker (Doxasin) in BPH appraised by pressure-flow (CLIM) analysis. Neurourol Urodyn 10: 295296, 1991.

25. Scholtmeijer RJ, and van Mastrigt R: The effect of oxyphenonium bromide and oxybutynin $\mathrm{HCl}$ on detrusor contractility and reflux in children with vesicoureteral reflux and detrusor instability. J Urol 146: 660-662, 1991.

26. Kranse R, van Mastrigt R, and Rollema HJ: Resolution and specificity of parameters characterizing bladder outlet obstruction. Neurourol Urodyn 11: 395-397, 1992.

27. Schäfer W, Hermanns R, Langen $\mathrm{PH}$, Abrams $\mathrm{PH}$, Chapple CR, and Stott M: Urodynamic analysis of drug effects on bladder voiding function: statistical significance and clinical relevance of changes. Neurourol Urodyn 10: 288-289, 1991.

28. Schäfer W: Comparison of simple concepts of pressure/flow analysis: URA versus linear PURR and $\mathrm{p} / \mathrm{Q}$ diagram. Neurourol Urodyn 11: 397-398, 1992.

29. Schäfer W: A new concept for simple but specific grading of bladder outflow condition independent from detrusor function. J Urol 149: A574, 1993.

30. Griffiths DJ: Editorial comment to article. ${ }^{7}$ Neurourol Urodyn 8: 43-44, 1989 